\title{
The utility of exome sequencing for genetic diagnosis in a familial microcephaly epilepsy syndrome
}

\author{
Laura M McDonell ${ }^{1 \dagger}$, Jodi Warman Chardon ${ }^{2+}$, Jeremy Schwartzentruber ${ }^{3}$, Denise Foster ${ }^{4}$, Chandree L Beaulieu ${ }^{1}$, \\ FORGE Canada Consortium', Jacek Majewski ${ }^{5}$, Dennis E Bulman ${ }^{1,6}$ and Kym M Boycott ${ }^{1,2,6^{*}}$
}

\begin{abstract}
Background: Despite remarkable advances in genetic testing, many adults with syndromic epilepsy remain without a molecular diagnosis. The challenge in providing genetic testing for this patient population lies in the extensive genetic heterogeneity associated with epilepsy. Even for the subset of epilepsy patients that present with a defining feature, such as microcephaly, the number of possible genes that would require interrogation by Sanger sequencing is extensive and often prohibitively expensive.

Case presentation: We report a family of French Canadian descent with four adult children affected with severe intellectual disability, epilepsy and microcephaly born to consanguineous parents and evaluated by the Genetics Service to provide informed genetic counseling to unaffected family members regarding possible recurrence risks. We used whole-exome sequencing (WES) of DNA from one affected sibling as a first-line diagnostic tool and compared the prioritization of variants using two strategies: 1) focusing on genes with homozygous variants; and, 2) focusing on genes associated with microcephaly. Both approaches prioritized the same homozygous novel frameshift mutation (p.Arg608Serfs*26) in WDR62, a gene known to cause autosomal recessive primary microcephaly. Sanger sequencing confirmed the presence of the homozygous mutation in the other three affected siblings.

Conclusions: WES and subsequent filtering of the rare variants in a single affected family member led to the rapid and cost-effective identification of a novel homozygous frameshift mutation in WDR62, thereby explaining the severe neurodevelopmental disorder in this family and facilitating genetic counseling. Our findings support WES as an effective first-line diagnostic tool in families presenting with rare genetically heterogeneous neurological disorders.
\end{abstract}

Keywords: Primary microcephaly, Epilepsy, Whole-exome sequencing, WDR62

\section{Background}

Although up to $70 \%$ of patients with epilepsy have an underlying genetic cause [1], most patients with epilepsy will not receive a molecular diagnosis. Genetic testing for epilepsies is challenging since genetic heterogeneity for this group of conditions is significant. For instance, epilepsy can be caused by mutations in over 260 genes

\footnotetext{
*Correspondence: kboycott@cheo.on.ca

${ }^{\dagger}$ Equal contributors

'Children's Hospital of Eastern Ontario Research Institute, University of Ottawa, Ottawa, Ontario, Canada

2Department of Genetics, Children's Hospital of Eastern Ontario, 401 Smyth Road, Ottawa, ON K1H 8 L1, Canada

Full list of author information is available at the end of the article
}

and an accurate diagnosis can be particularly difficult with nonspecific epilepsy phenotypes [2]. Even when epilepsy is associated with additional features, such as microcephaly, the number of genes potentially responsible can still be significant and assessing each gene in turn by Sanger sequencing would be time-consuming and expensive. However, establishing a molecular diagnosis is important for informed genetic counseling, prenatal testing, insight into natural history and increasingly for therapeutic management as there are now many instances where medications are tailored based on molecular results [3-5].

Whole exome sequencing (WES) has emerged as a very successful tool for novel disease gene discovery [6] 
and its utility in the rapid and cost-effective analysis of heterogeneous disorders is being established. Both a WES approach and the application of targeted panels of channelopathy or encephalopathy genes have been successful in identifying the molecular cause for many patients with rare epilepsies [2,7]. In addition, WES may offer a rapid and less expensive first line test to establish a molecular diagnosis for disabled patients residing in remote areas where ready access to standard diagnostic assessments can be more challenging. We report here the utility of WES as the initial diagnostic tool for a consanguineous family with four affected adult children with epilepsy, microcephaly and severe intellectual disability from a remote area of Canada.

\section{Case presentation}

\section{Clinical findings}

Four affected siblings (two females and two males) from a consanguineous French Canadian family presented in their 40s and 50s to a satellite genetics clinic for assessment to facilitate genetic counseling for extended family members (Figure 1A). Two developmentally normal brothers died in an accidental fire and one living brother is unaffected. The parents were from an isolated community and were distantly related. The four siblings had moderate to severe intellectual disability, epilepsy and microcephaly (Table 1). A more severe phenotype was seen in the two male siblings, including medically refractory seizures, aggression and self-injury. Due to the difficulty of performing MRI in a remote region and the long differential diagnosis, DNA was sent for WES as an initial investigation.

\section{Genetic studies}

Genomic DNA was extracted from whole blood obtained from the four affected individuals using the QIAamp DNA Blood Kit (Qiagen, CA, USA). DNA from Patient II1 underwent WES. Using target capture with the Agilent

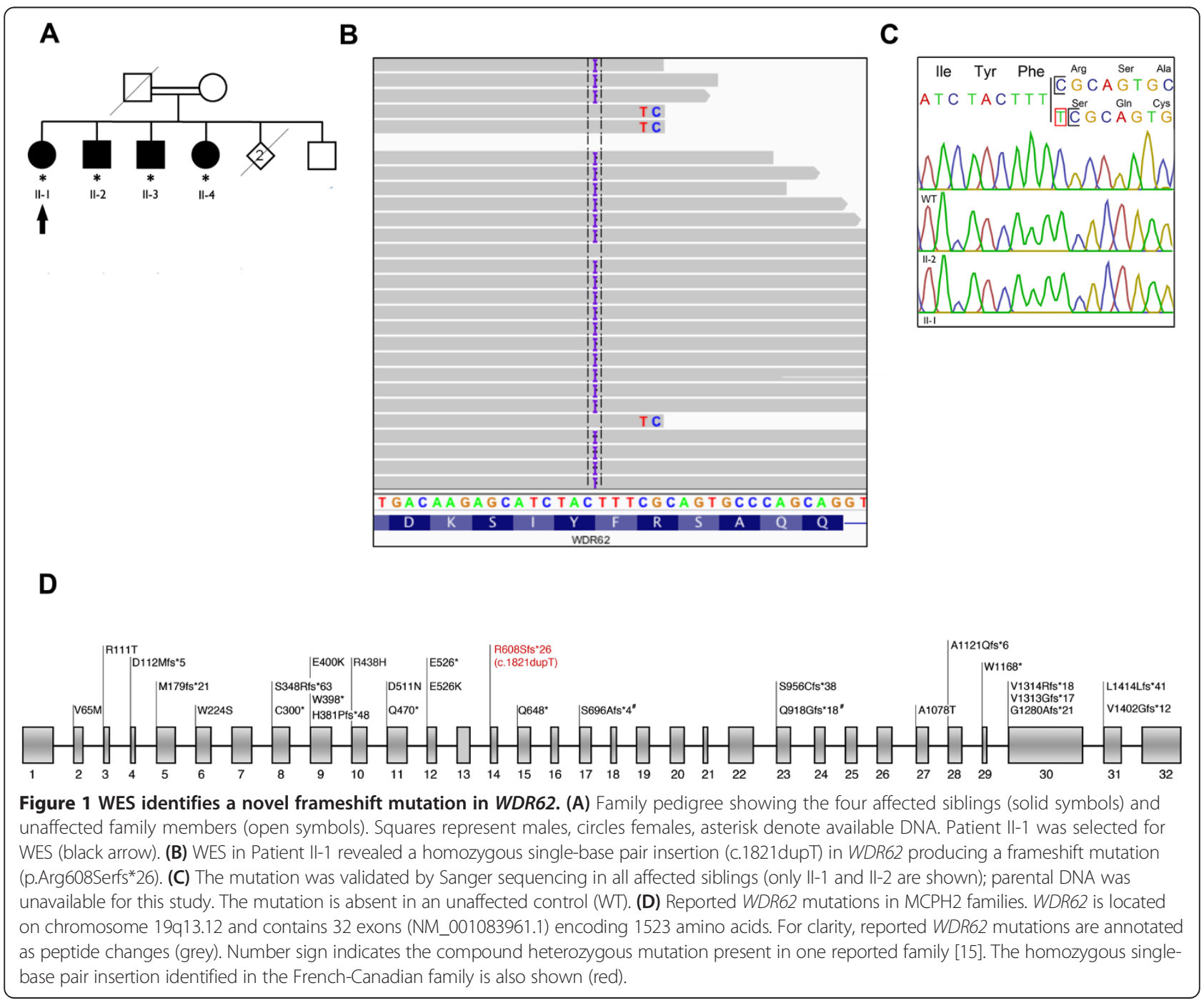


Table 1 Clinical and neuroimaging features of the four MCPH2 patients

\begin{tabular}{|c|c|c|c|c|}
\hline Patient & $\mathrm{II}-1$ & $\mathrm{II}-2$ & II-3 & II-4 \\
\hline Gender & $\mathrm{F}$ & M & M & $\mathrm{F}$ \\
\hline Age at assessment (yrs) & 59 & 56 & 55 & 53 \\
\hline \multicolumn{5}{|l|}{ Clinical features } \\
\hline Height (cm) & 158 & 154 & 166 & 154 \\
\hline Height percentile & 10-25th & $<5$ th & 5 th & 5-10th \\
\hline Occipito-frontal circumference $(\mathrm{cm})$ & 48.5 & 52 & 51 & 48 \\
\hline Occipito-frontal circumference (SD) & -4 to -5 SD & -2 to $-3 \mathrm{SD}$ & $-3 \mathrm{SD}$ & -4 to -5 SD \\
\hline Sloping forehead & + & + & + & + \\
\hline Intellectual disability & Moderate-severe & Severe & Severe & Moderate-severe \\
\hline Behaviour & Pleasant & Self injurious behaviour & Self injurious behaviour & Pleasant \\
\hline Tone & Normal & Hypertonia & Hypertonia & Normal \\
\hline Sensory exam & Normal & Normal & Normal & Normal \\
\hline Reflexes & Normal & Hyperreflexia/ankle clonus & Hyperreflexia/ankle clonus & Normal \\
\hline Bladder/bowel incontinence & $+/-$ & $+/+$ & $+/+$ & $+/-$ \\
\hline \multicolumn{5}{|l|}{ Neuroimaging features } \\
\hline Microcephaly & + & $\mathrm{Nd}$ & $\mathrm{Nd}$ & + \\
\hline Polymicrogyria & - & $\mathrm{Nd}$ & $\mathrm{Nd}$ & - \\
\hline Cerebellar hypoplasia & - & $\mathrm{Nd}$ & $\mathrm{Nd}$ & - \\
\hline Cortical thickenng & - & $\mathrm{Nd}$ & $\mathrm{Nd}$ & - \\
\hline Corpus callosum hypoplasia & - & $\mathrm{Nd}$ & $\mathrm{Nd}$ & - \\
\hline
\end{tabular}

SureSelect $50 \mathrm{Mb}$ All Exon kit (Agilent Technologies, Santa Clara, CA) and sequencing of $100 \mathrm{bp}$ paired end reads on Illumina Hiseq, we generated over $15 \mathrm{~Gb}$ of sequence for the sample such that approximately $90 \%$ of the coding bases of the exome defined by the consensus coding sequence (CCDS) project were covered by at least 20 reads. WES data was analyzed as previously described [8] and non-synonymous variants (frameshift and non-frameshift indels, single nucleotide variants (SNV) including stop-gain and missense SNVs, and splicing and splicing-extending variants) were identified as rare when they had a frequency of less than $1 \%$ in the 1000 genomes pilot release (Nov 2010) and in 100 in-house controls. We then compared two approaches to examine this subset of WES variants (Figure 2).

Following our preliminary filtering steps that identified 183 rare non-synonymous variants, we examined the sequencing data for homozygous variants as the pedigree was consistent with autosomal recessive inheritance and the parents were distantly related (see Method 1, Figure 2). WES identified ten exome-wide homozygous variants including a rare variant in WDR62, encoding a protein essential to cerebral cortex development and known to cause microcephaly [9-11] (Figure 1B) and thus felt to be a strong candidate gene for the disorder in this family. The WDR62 mutation identified is a novel homozygous single-base pair insertion NM_001083961.1:c.1821dupT) producing a frameshift mutation (p.Arg608Serfs"26) in exon 14 (Figure 1C). The protein-truncating mutation is absent from the 6500 exomes in the NHLBI Exome Variant Server. We next examined the WES data using a second approach to identify all rare variants in genes known to be associated with epilepsy and microcephaly (see Method 2, Figure 2); the same mutation in WDR62 was identified as the only candidate.

The mutation in WDR62 was validated by Sanger sequencing in the other three siblings. After the diagnosis, unenhanced MRI of the brain was performed in both sisters and demonstrated microcephaly without polymicrogyria, cerebellar hypoplasia, cortical thickening or corpus callosum hypoplasia. Patient II-2 died suddenly of a cardiac arrest but was not known to have cardiac disease prior to the fatal event; the family declined an autopsy.

\section{Discussion}

Primary autosomal recessive microcephaly $(\mathrm{MCPH}$, OMIM 251200) is a genetically heterogeneous group of disorders characterized by congenital microcephaly, cognitive impairment and variable epilepsy [12]. Mutations in WDR62 are associated with primary microcephaly-2 (MCPH2, OMIM 604317), which is believed to account for $10 \%$ of all cases of MCPH [13]. Clinical features of $\mathrm{MCPH} 2$ include epilepsy, marked cognitive impairment, 


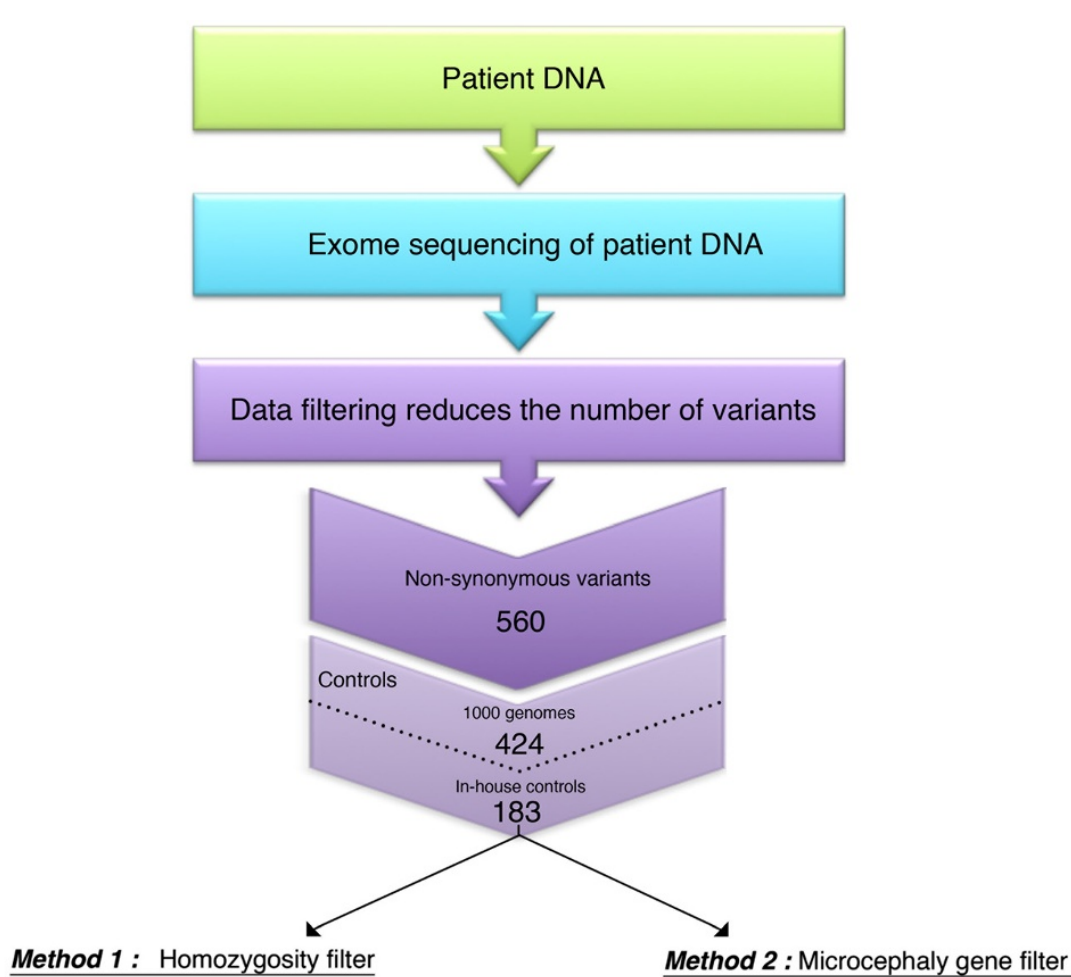

Step 1. Rare non-synonymous variants: 183

Step 1. Rare non-synonymous variants: 183 $\downarrow$

Step 2. Homozygous variants: 10 $\downarrow$

Step 2. MCPH genes with variants: WDR62

Step 3. Variants in known MCPH genes: 1 (identified in WDR62)

Figure 2 Exome sequencing workflow. Exome sequencing was performed on isolated DNA from Patient II-1. The data was filtered to identify non-synonymous sequence variants including frameshift and non-frameshift indels, single nucleotide variants (SNV) including stop-gain and missense SNVs, and splicing and splicing-extending variants. Variants with a frequency of less than $1 \%$ in the 1000 genomes pilot release (Nov 2010) and in 100 in-house controls were then identified. The first method of analysis focused on rare homozygous variants (Method 1) and a second, simpler approach, focused only on rare variants in disease genes known to cause microcephaly/epilepsy (Method 2). Both methods identified the homozygous mutation in WDR62 as the cause of the neurodevelopmental disorder in this family.

incontinence, sloping forehead and prominent ears. Radiological features are variable and may include polymicrogyria, corpus callosum hypoplasia, heterotopias, pachygyria with cortical thickening, lissencephaly and schizencephaly, although patients can present with isolated microcephaly [14-18]. To date, 34 families have been identified with mutations in WDR62, the reported affected individuals ranging in age from infancy to midteens [14-18].We present here the oldest patients known to have WDR62 mutations associated with $\mathrm{MCPH}$, providing additional insight into the natural history and phenotypic spectrum of this disorder. It is unclear whether the sudden cardiac death for Patient II-2 is associated with WDR62 mutations or an unrelated cardiac event. Of the mutations in WDR62 reported thus far, approximately half have been frameshift mutations, as described here, distributed throughout the gene and predicted to result in premature truncation of the protein (Figure 1C).

At least ten genes have been associated with $\mathrm{MCPH}$ [ASPM, MCPH1, WDR62, CDK5RAP2, CASC5, CENPJ, STIL, CEP135, CEP152 and ZNF335] and are implicated in proliferation and migration of neuronal progenitors during embryonic cortical development [19]. Clinicalradiological features have not been loci-specific and $\mathrm{MCPH}$ patients remain phenotypically indistinguishable [13]. Thus, conventional molecular testing can be a long and expensive process and may not yield a diagnosis. Currently, sequential analysis of the eight clinically available $\mathrm{MCPH}$ genes would total more than $\$ 22,000$ USD. Alternatively, eight of the ten MCPH genes could be sequenced as part of a microcephaly panel for $\$ 7,000$ USD (www.centogene.com accessed November $6^{\text {th }}, 2013$, eight genes). Comparatively, WES would 
interrogate all ten microcephaly genes and is currently available in clinical laboratories at \$5000 USD per patient, making it a cost-effective solution for rapid diagnosis in the clinic.

\section{Conclusion}

We studied four siblings from a consanguineous French Canadian family presenting with microcephaly, severe developmental delay and epilepsy. Given their relatively nonspecific phenotype which did not suggest a single likely candidate gene, sequential gene testing was not undertaken. Alternatively, WES provided a cost-effective and rapid method to identify the genetic cause of epilepsy and microcephaly in this family. We highlight, that particularly for patients in remote areas, WES via DNA blood/saliva offers a non-invasive and readily accessible method for shortening the diagnostic process for these patients.

\section{Consent}

Informed consent was obtained for participation in the Finding of Rare Disease Genes (FORGE) Canada study. The Research Ethics Board of the Children's Hospital of Eastern Ontario approved this study in accordance with the Declaration of Helsinki. A copy of the written consent is available for review by the Editor of this journal.

\section{Competing interests}

The authors declare that they have no competing interests.

\section{Authors' contributions}

KMB and DEB directed the study. JWC, DF and KMB provided clinical data. LMM performed Sanger sequencing, genotyping studies and exome variant analysis supervised by KMB and DEB. JS and JM performed exome variant calling analysis. The manuscript was written by LMM, JWC and KMB. KMB is lead of the FORGE Canada Consortium and is assisted by CLB. All authors read and approved the final manuscript.

\section{Acknowledgements \\ The authors would first like to thank the study patients, their family and their caring guardians, without whose participation this work would not be possible. This work was funded by the Government of Canada through Genome Canada, the Canadian Institutes of Health Research (CIHR) and the Ontario Genomics Institute (OGI-049) (to KMB). Additional funding was provided by Genome Quebec and Genome British Columbia (to KMB). The authors wish to acknowledge the contribution of the high throughput sequencing platform of the McGill University and Génome Québec Innovation Centre, Montreal, Canada. This work was selected for study by the FORGE Canada Steering Committee, consisting of K. Boycott (U. Ottawa), J. Friedman (U. British Columbia), J. Michaud (U. Montreal), F. Bernier (U. Calgary), M. Brudno (U. Toronto), B. Fernandez (Memorial U.), B. Knoppers (McGill U.), M. Samuels (U. de Montreal), and S. Scherer (U. Toronto). LMM is supported by a Frederick Banting Graduate Scholarship from CIHR. KMB is supported by a Clinical Investigatorship Award from the CIHR Institute of Genetics.}

\section{Author details}

${ }^{1}$ Children's Hospital of Eastern Ontario Research Institute, University of Ottawa, Ottawa, Ontario, Canada. ${ }^{2}$ Department of Genetics, Children's Hospital of Eastern Ontario, Ottawa, Ontario, Canada. ${ }^{3}$ McGill University and Genome Quebec Innovation Centre, Montréal, Quebec, Canada. ${ }^{4}$ Algoma Public Health, Sault Ste Marie, Ontario, Canada. ${ }^{5}$ Department of Human
Genetics, McGill University, Montréal, Quebec, Canada. ${ }^{6}$ Department of Pediatrics, University of Ottawa, Ottawa, Ontario, Canada.

Received: 11 November 2013 Accepted: 22 January 2014 Published: 31 January 2014

\section{References}

1. Hildebrand MS, Dahl HH, Damiano JA, Smith RJ, Scheffer IE, Berkovic SF: Recent advances in the molecular genetics of epilepsy. J Med Genet 2013, 50(5):271-279.

2. Lemke JR, Riesch E, Scheurenbrand T, Schubach M, Wilhelm C, Steiner I, Hansen J, Courage C, Gallati S, Burki S, Strozzi S, Simonetti BG, Grunt S, Steinlin M, Alber M, Wolff M, Klopstock T, Prott EC, Lorenz R, Spaich C, Rona S, Lakshminarasimhan M, Kroll J, Dorn T, Kramer G, Synofzik M, Becker F, Weber YG, Lerche $H$, Bohm D, et al: Targeted next generation sequencing as a diagnostic tool in epileptic disorders. Epilepsia 2012, 53(8):1387-1398.

3. Bainbridge MN, Wiszniewski W, Murdock DR, Friedman J, Gonzaga-Jauregui C, Newsham I, Reid JG, Fink JK, Morgan MB, Gingras MC, Muzny DM, Hoang LD, Yousaf S, Lupski JR, Gibbs RA: Whole-genome sequencing for optimized patient management. Sci Trans/ Med 2011, 3(87):87re83.

4. Need AC, Shashi V, Hitomi Y, Schoch K, Shianna KV, McDonald MT, Meisler $\mathrm{MH}$, Goldstein DB: Clinical application of exome sequencing in undiagnosed genetic conditions. J Med Genet 2012, 49(6):353-361.

5. Le Gal F, Korff CM, Monso-Hinard C, Mund MT, Morris M, Malafosse A, Schmitt-Mechelke T: A case of SUDEP in a patient with Dravet syndrome with SCN1A mutation. Epilepsia 2010, 51(9):1915-1918.

6. Boycott KM, Vanstone MR, Bulman DE, MacKenzie AE: Rare-disease genetics in the era of next-generation sequencing: discovery to translation. Nat Rev Genet 2013, 14(10):681-691.

7. Veeramah KR, Johnstone L, Karafet TM, Wolf D, Sprissler R, Salogiannis J, Barth-Maron A, Greenberg ME, Stuhlmann T, Weinert S, Jentsch TJ, Pazzi M, Restifo LL, Talwar D, Erickson RP, Hammer MF: Exome sequencing reveals new causal mutations in children with epileptic encephalopathies. Epilepsia 2013, 54(7):1270-1281.

8. Lines MA, Huang L, Schwartzentruber J, Douglas SL, Lynch DC, Beaulieu C, Guion-Almeida ML, Zechi-Ceide RM, Gener B, Gillessen-Kaesbach G, Nava C, Baujat G, Horn D, Kini U, Caliebe A, Alanay Y, Utine GE, Lev D, Kohlhase J, Grix AW, Lohmann DR, Hehr U, Bohm D, Majewski J, Bulman DE, Wieczorek D, Boycott KM: Haploinsufficiency of a spliceosomal GTPase encoded by EFTUD2 causes mandibulofacial dysostosis with microcephaly. A J Hum Genet 2012, 90(2):369-377.

9. Yu TW, Mochida GH, Tischfield DJ, Sgaier SK, Flores-Sarnat L, Sergi CM, Topcu M, McDonald MT, Barry BJ, Felie JM, Sunu C, Dobyns WB, Folkerth $\mathrm{RD}$, Barkovich AJ, Walsh CA: Mutations in WDR62, encoding a centrosomeassociated protein, cause microcephaly with simplified gyri and abnormal cortical architecture. Nat Genet 2010, 42(11):1015-1020.

10. Bilguvar K, Ozturk AK, Louvi A, Kwan KY, Choi M, Tatli B, Yalnizoglu D, Tuysuz B, Caglayan AO, Gokben S, Kaymakcalan H, Barak T, Bakircioglu M, Yasuno K, Ho W, Sanders S, Zhu Y, Yilmaz S, Dincer A, Johnson MH, Bronen RA, Kocer N, Per H, Mane S, Pamir MN, Yalcinkaya C, Kumandas S, Topcu M, Ozmen M, Sestan $\mathrm{N}$, et al: Whole-exome sequencing identifies recessive WDR62 mutations in severe brain malformations. Nature 2010, 467(7312):207-210.

11. Nicholas AK, Khurshid M, Desir J, Carvalho OP, Cox JJ, Thornton G, Kausar R, Ansar M, Ahmad W, Verloes A, Passemard S, Misson JP, Lindsay S, Gergely F, Dobyns WB, Roberts E, Abramowicz M, Woods CG: WDR62 is associated with the spindle pole and is mutated in human microcephaly. Nat Genet 2010, 42(11):1010-1014.

12. Woods CG, Bond J, Enard W: Autosomal recessive primary microcephaly (MCPH): a review of clinical, molecular, and evolutionary findings. $A J$ Hum Genet 2005, 76(5):717-728.

13. Mahmood S, Ahmad W, Hassan MJ: Autosomal Recessive Primary Microcephaly (MCPH): clinical manifestations, genetic heterogeneity and mutation continuum. Orphan J Rare Dis 2011, 6:39.

14. Kousar R, Hassan MJ, Khan B, Basit S, Mahmood S, Mir A, Ahmad W, Ansar M: Mutations in WDR62 gene in Pakistani families with autosomal recessive primary microcephaly. BMC Neurol 2011, 11:119.

15. Murdock DR, Clark GD, Bainbridge MN, Newsham I, Wu YQ, Muzny DM, Cheung SW, Gibbs RA, Ramocki MB: Whole-exome sequencing identifies compound heterozygous mutations in WDR62 in siblings with recurrent polymicrogyria. Am J Med Genet A 2011, 155A(9):2071-2077. 
16. Bacino CA, Arriola LA, Wiszniewska J, Bonnen PE: WDR62 missense mutation in a consanguineous family with primary microcephaly. Am J Med Genet A 2012, 158A(3):622-625

17. Memon MM, Raza SI, Basit S, Kousar R, Ahmad W, Ansar M: A novel WDR62 mutation causes primary microcephaly in a Pakistani family. Mol Biol Rep 2013, 40(1):591-595.

18. Sajid Hussain M, Marriam Bakhtiar S, Farooq M, Anjum I, Janzen E, Reza Toliat M, Eiberg H, Kjaer KW, Tommerup N, Noegel AA, Nurnberg P, Baig SM, Hansen L: Genetic heterogeneity in Pakistani microcephaly families. Clin Genet 2013, 83(5):446-451.

19. Wollnik B: A common mechanism for microcephaly. Nat Genet 2010, 42(11):923-924.

doi:10.1186/1471-2377-14-22

Cite this article as: McDonell et al:: The utility of exome sequencing for genetic diagnosis in a familial microcephaly epilepsy syndrome. BMC Neurology 2014 14:22.

\section{Submit your next manuscript to BioMed Central and take full advantage of:}

- Convenient online submission

- Thorough peer review

- No space constraints or color figure charges

- Immediate publication on acceptance

- Inclusion in PubMed, CAS, Scopus and Google Scholar

- Research which is freely available for redistribution 